\title{
Prevention of vaginal and rectal herpes simplex virus type 2 transmission in mice: mechanism of antiviral action
}

\author{
Rafael Ceña-Diez ${ }^{1, *}$ \\ Enrique Vacas-Córdoba ${ }^{1, *}$ \\ Pilar García-Broncano ${ }^{1,2}$ \\ FJ de la Mata ${ }^{3}$ \\ Rafael Gómez ${ }^{3}$ \\ Marek Maly ${ }^{4}$ \\ $M^{a}$ Ángeles Muñoz-Fernández ${ }^{1}$
}

'Molecular Immunobiology Laboratory, General Universitary

Hospital Gregorio Marañon, Health Research Institute Gregorio Marañon, Spanish HIV HGM BioBank, Networking Research Center on Bioengineering, Biomaterials and Nanomedicine (CIBER-BBN), ${ }^{2}$ Viral and Immune Infection Unit Center, Institute of Health Carlos III, Majadahonda Campus, Molecular Immunobiology Laboratory, General Universitary Hospital Gregorio Marañon, ${ }^{3}$ Organic and Inorganic Chemistry Department, Alcala University, University Campus Alcala de Heneras, Networking Research Center on Bioengineering, Biomaterials and Nanomedicine (CIBER-BBN), Madrid, Spain; ${ }^{4}$ Faculty of Science, J.E. Purkinje University, Ústí nad Labem, Czech Republic

*These authors contributed equally to this work

Correspondence: $M^{a}$ Ángeles MuñozFernández

Spain HIV HGM BioBank, Hospital

General Universitario Gregorio Marañón. IISGM. BioBank. CIBER BBN,

C/Dr. Esquerdo 46, 28007 Madrid, Spain

Tel +34 9l 5868565

Email mmunoz.hgugm@gmail.com
This article was published in the following Dove Press journal:

International Journal of Nanomedicine

19 May 2016

Number of times this article has been viewed

Abstract: Topical microbicides to stop sexually transmitted diseases, such as herpes simplex virus type 2 (HSV-2), are urgently needed. The emerging field of nanotechnology offers novel suitable tools for addressing this challenge. Our objective was to study, in vitro and in vivo, antiherpetic effect and antiviral mechanisms of several polyanionic carbosilane dendrimers with anti-HIV-1 activity to establish new potential microbicide candidates against sexually transmitted diseases. Plaque reduction assay on Vero cells proved that G2-S16, G1-S4, and G3-S16 are the dendrimers with the highest inhibitory response against HSV-2 infection. We also demonstrated that our dendrimers inhibit viral infection at the first steps of HSV-2 lifecycle: binding/entry-mediated events. G1-S4 and G3-S16 bind directly on the HSV-2, inactivating it, whereas G2-S16 adheres to host cell-surface proteins. Molecular modeling showed that G1-S4 binds better at binding sites on gB surface than G2-S16. Significantly better binding properties of G1-S4 than G2-S16 were found in an important position for affecting transition of $\mathrm{gB}$ trimer from $\mathrm{G} 1-\mathrm{S} 4$ prefusion to final postfusion state and in several positions where G1-S4 could interfere with $\mathrm{gB} / \mathrm{gH}-\mathrm{gL}$ interaction. We demonstrated that these polyanionic carbosilan dendrimers have a synergistic activity with acyclovir and tenofovir against HSV-2, in vitro. Topical vaginal or rectal administration of G1-S4 or G2-S16 prevents HSV-2 transmission in BALB/c mice in values close to $100 \%$. This research represents the first demonstration that transmission of HSV-2 can be blocked by vaginal/rectal application of G1-S4 or G2-S16, providing a step forward to prevent HSV-2 transmission in humans.

Keywords: nanotechnology, dendrimers, G1-S4, G2-S16, HSV-2, microbicide

\section{Introduction}

Genital herpes is the most prevalence sexually transmitted disease (STD). There are 417 million herpes simplex virus type 2 (HSV-2)-infected people worldwide and approximately 19 million of new infections occur each year. ${ }^{1}$ The HSV-2 is associated with the appearance of sores and painful ulcers around the genital area or rectum ${ }^{2}$ and its viral genome is maintained within neurons of the sensory sacral ganglia in latency. ${ }^{3}$ Herpes infection is incurable; it can be mitigated or modulated through current antiviral treatment, but latent infection cannot be eliminated. ${ }^{4}$ Moreover, no effective human vaccine candidates to date in clinical trials have been licensed for use in humans. ${ }^{1,5}$ Therefore, prevention strategies are essential within the fight against the STD, with the development of safe topical microbicides that allow women to actively avoid STD acquisition, especially when HSV-2 infection is associated with a three- to fourfold increased risk of HIV infection. ${ }^{6}$ 
Dendrimers, nanotech-derived particles characterized by their high branching, defined size, and three-dimensional structure, showed potential as HIV-1 and HIV-2 microbicide candidates. ${ }^{7-11}$ Several dendrimers, functionalized with chemical groups at their periphery, were evaluated as antiviral agents against HSV-2. ${ }^{12}$ Notably, sulfonate-terminated anionic poly(lysine)-based dendrimer SPL7013, formulated as VivaGel ${ }^{\mathrm{TM}}$, showed efficacy against HIV and HSV in clinical trials. ${ }^{13}$ We previously showed that dendrimers act at the entry step of HIV-1 infection, preventing the establishment of viral infection. ${ }^{7,8,14}$ Entry inhibitors could be excellent candidates for the development of topical microbicides since they block HSV-2 transmission at the mucosal surface, thus providing a method of prophylactic intervention. ${ }^{13}$

Polyanionic carbosilane dendrimers showed antiviral activity and potential as microbicides. ${ }^{7,8,14}$ They are distinguished from other dendrimers in their high apolarity of central core and high mobility of peripheral branches, features that turn them into outstanding candidates to be used in biomedical applications. Carbosilane dendrimers were effective to inhibit HIV infection and transmission within genital mucosa and were safe in mice models. ${ }^{7,8,14}$ Thus, potent antiviral activity of these nanosystems against other sexually transmitted pathogens, such as HSV-2, could be extremely important in order to develop broad-spectrum effective microbicides.

We have studied in vitro and in vivo the antiherpetic effect and antiviral mechanisms of polyanionic dendrimers to establish a new potential microbicide that could stop HSV-2 spreading through sexual contact. We focus on mechanism of action against HSV-2 infection of these dendrimers and, most relevant, we show that vaginal and rectal application of a gel formulation of dendrimers protect against HSV-2 challenge in $\mathrm{BALB} / \mathrm{c}$ mice.

\section{Materials and methods Compounds}

G1-C8, G1-S4, G3-S16, G2-NF16, G2-S16, G2-STE16, G2-CTE16, and G2-S24P were synthesized according to the methods reported by Dendrimers for Biomedical Applications group (Figure S1). ${ }^{8,9,14,15}$ Eight dendrimers were dissolved in distilled water in a final concentration of $1 \mathrm{mM}$. Dilutions to $\mu \mathrm{M}$ range were generated in distilled water from the stock.

ACV was purchased from GlaxoSmithKline (Middlesex, UK), TFV disoproxil fumarate (Gilead Science, Foster City, CA, USA) was obtained in tablet form. Dextran (SigmaAldrich, St Louis, MO, USA), a harmless molecule, and dimethyl sulfoxide were used as negative and positive control of cellular toxicity, respectively.

\section{Cells and viruses}

Vero cells (ATCC CCL-81, Manassas, VA, USA), African green monkey kidney cells, VK2/E6E7 (ATCC CRL-2616, Manassas, VA, USA), human epithelial cell line from vaginal mucosa tissue and HEC-1A (ATCC HTB-112, Manassas, VA, USA), epithelial cell line derived from a human endometrial carcinoma, were grown as previously described. ${ }^{16}$ HSV-2 strain 333 isolate was provided by Dr A. Alcamí (Severo Ochoa Centre for Molecular Biology (CBMSO), Spain). Stock of HSV-2 was prepared and titrated by plaque assay ${ }^{16}$ and stored at $-80^{\circ} \mathrm{C}$. Human cell lines have been used following the principles outlined in the Declaration of Helsinki, and no ethics committee approval was required for this set of experiments.

\section{Cell viability and antiviral assays}

Cell viability was determined by MTT assay (Sigma-Aldrich) at 24 hours postexposure according of manufacturer's instructions.

To screen the potential anti-HSV-2 activities of selected dendrimers, $60 \times 10^{3}$ Vero or HEC-1A cells were seeded in 48-well plates. After 24 hours, cells were treated with dendrimers for 1 hour at $37^{\circ} \mathrm{C}$ before HSV-2 infection at a multiplicity of infection of 0.1 . After 6 hours, cells were washed to remove unabsorbed virus. At 30-40 hours HSV-2 pi, culture supernatants were collected and their infectivity was assessed by plaque reduction assay. Briefly, Vero cells, seeded in six-well plates, were treated with $100 \mu \mathrm{L}$ of various supernatant dilutions for 1 hour at $37^{\circ} \mathrm{C}$. Then, Vero cells were covered with Dulbecco's Modified Eagle's Medium (DMEM) containing 2\% fetal bovine serum (FBS) and $0.4 \%$ of immunoglobulin (Ig) (Beriglobin; Behring, King of Prussia, PA, USA) and incubated for 48 hours. Subsequently, Vero cells were stained with $0.03 \%$ methylene blue in distilled water and viral plaques were counted. VK2/E6/E7 cells seeded in 24-well plates were exposed to maximum nontoxic concentration of dendrimers for 1 hour before HSV-2 exposure at an inoculum to $150 \mathrm{PFU} /$ well. VK2/E6/E7 cells were incubated for 2 hours at $37^{\circ} \mathrm{C}$ and then washed and overlaid with DMEM containing $0.4 \%$ human Ig. Viral plaques were counted after 48 hours and the percentages of plaques relative to plaques on control wells were calculated.

\section{Effect of $\mathrm{pH}$ in anti-HSV-2 activity}

Selected dendrimers were incubated at pHs 3, 4, 5.5, and 7 solutions of PBS for 1 hour. Afterward, Vero cells were pretreated 1 hour with maximum dendrimers and infected with $150 \mathrm{PFU} /$ well HSV-2 for 2 hours. Then, cells were washed and covered with $2 \%$ FBS DMEM containing human 
Ig. HSV-2 infection, measured as number of viral plaques, was determined at 48 hours pi.

\section{Time-of-addition experiment}

Vero cells were infected with HSV-2 and antiviral compounds and dendrimers were added at $0,1,2,4,6,8$, and 24 hours pi. After 2 hours pi, cells were washed and covered with medium containing human Ig. The viral plaques were counted after 48 hours to determine the HSV-2 infection.

\section{Attachment assay}

The effect of dendrimers on viral attachment was assessed as previously described. ${ }^{17}$ Briefly, prechilled Vero cell monolayers in 24 -well plates $\left(175 \times 10^{3}\right.$ cells/well $)$ were treated with dendrimers for 1 hour at $4^{\circ} \mathrm{C}$ and infected with $150 \mathrm{PFU} /$ well HSV-2 for 2 hours at $4^{\circ} \mathrm{C}$. Cells were washed with cold $2 \% \mathrm{FBS} / \mathrm{DMEM}$ to remove unattached dendrimers and unabsorbed HSV-2 and overlaid with medium containing human Ig. After 48 hours at $37^{\circ} \mathrm{C}$, cells were stained with methylene blue and viral plaques were counted.

\section{HSV-2 inactivation assay}

Dendrimers were incubated with $10^{4} \mathrm{PFU}$ of $\mathrm{HSV}-2$ at $4^{\circ} \mathrm{C}$ for 30 minutes, 1 or 2 hours. After incubation, 150 PFU of HSV-2 treated with dendrimers at concentration not active in the antiviral assay were added to Vero cells in order of their titration. The viral plates were stained and counted at 48 hours pi.

\section{Binding of dendrimers to cell surface molecules}

Vero cells were pretreated with dendrimers for 1 hour. After incubation, cells were extensively washed and infected with 150 PFU of HSV-2. After 48 hours pi, cells were stained and HSV-2 plaques were counted.

\section{Molecular modeling of dendrimers with HSV-2 surface protein gB}

Three-dimensional computer models of G2-16 and G1-S4 structures were created using dendrimer builder, as implemented in Materials Studio software package from BIOVIA (San Diego, CA, USA). RESP charges ${ }^{18}$ were calculated using R.E.D.-IV tools ${ }^{19}$ and GAMESS. ${ }^{20}$ GAFF force field, was used for parameterisation of dendrimers. Missing force field parameters were fitted by minimizing the differences between quantum mechanics and force field-based relative energies of properly chosen molecular fragments. Quantum mechanics energies were calculated at MP2/HF/6-31G** level of theory using
GAMESS and fitting was accomplished using paramfit from AMBER14 software. ${ }^{21}$ Slightly adjusted van der Waals parameters for Si atoms from MM3 force field were used. The protein components were parameterized using force field ff14SB. As the template for the main part of the simulated structure of residues $97-720$ of gB glycoprotein, the experimental structure of the HSV-1 gB (PDB:4BOM) was used. ${ }^{22}$ The protein part "RKPRNATPAPLREAPSANASVER", which is the short loop missing sequence 471-489 (Figure S2) extended at each end with 2 amino acids (aa), was created and simulated in explicit solvent for 28 nanoseconds. Then was attached to all three monomers of 4BOM structure and necessary mutations were performed to match primary sequence of the HSV-2 gB residues 98-720 (Figures S3 and $\underline{\mathrm{S} 4}$ ). The edited 4BOM structure was shortly simulated in explicit solvent ( 5 nanoseconds) to adjust properly the configurations of newly added residues. Then one monomer was chosen for consequent processing. The initial configuration of the missing residues 721-904 (C-terminal part) was generated and attached to the previously prepared residues 98-720 HSV-2 gB. HSV-2 gB monomer fragment residues 98-904 were simulated in implicit solvent for 153 nanoseconds with restrained part (residues 98-720, restraint $80 \mathrm{kcal} / \mathrm{mol}^{2}$ ) to obtain sufficiently stable configuration of the added C-terminal. Preparation of this HSV-2 gB part was finished by simulation in explicit water (66 nanoseconds) with restrained part (residues 98-720, restraint $20 \mathrm{kcal} /$ mol $\AA^{2}$ ) during the first 30 nanoseconds and the rest (36 nanoseconds) without any restraints. The added C-terminal was incorporated into the simulated structure just to "naturally" close this incomplete $\mathrm{gB}$ end and stabilize structure of simulated monomer. In reality, most of the gB part anchored in viral membrane has tertiary structure different from that obtained by our simulations. Preparation of N-terminal of the HSV-2 gB comprising residues 1-100 was as follows: the initial configuration of this protein part was generated based on known primary sequence and consequently the tertiary structure was estimated by using simulation in implicit solvent for 862 nanoseconds. Protein tertiary structure was consequently finalized by using simulation in explicit water (41 nanoseconds). Models of dendrimers were simulated in explicit solvent (G1-S4 for 10 nanoseconds, G2-S16 for 36 nanoseconds) and then the most representative conformations were chosen using cluster analysis of the resulting molecular dynamics (MD) trajectories. The dendrimer/ HSV-2 gB monomer fragment (residues 98-904) systems (cases A-F) were simulated in explicit water for 70 nanoseconds dendrimer/HSV-2 gB N-terminal (residues 1-100) for 50 nanoseconds. Initial configurations of the missing protein 
parts were generated using LEaP routine from Amber 14. Mutations and attachments of the missing parts to the main fragment as well as creation of the initial configurations of dendrimer-protein complexes and all visualizations were performed using UCSF Chimera software. ${ }^{23}$ Cluster analysis and postprocessing of MD trajectories were performed using cpptraj module from Amber 14.

\section{Simulation details}

In case of simulations in explicit solvent, the molecules were solvated in explicit water (TIP3P model) with the proper number of $\mathrm{Na}^{+}$and $\mathrm{Cl}^{-}$ions to preserve neutrality of the system and to ensure the correct ionic strength $(0.15 \mathrm{M}){ }^{24}$ First, the solvated molecular systems were minimized $(5,000$ steps with $2 \mathrm{kcal} /\left(\mathrm{mol} \AA^{2}\right)$ restraint $+5,000$ without restraint $)$, heated ( $200 \mathrm{ps}$ network virtual terminal) to $310 \mathrm{~K}$ and then equilibrated using MD simulation in NPT ensemble $(\mathrm{T}=310$ $\mathrm{K}, P=10^{5} \mathrm{~Pa}-$ lengths of simulations are mentioned in each case above). The first 0.5 nanoseconds with restrained solute ( $2 \mathrm{kcal} /\left[\mathrm{mol} \AA^{2}\right]$ restraint). Hydrogens were constrained with the SHAKE algorithm to allow 2 fs time step and Langevin thermostat with collision frequency $2 \mathrm{ps}^{-1}$ was used for all MD runs. ${ }^{25}$ The pressure relaxation time for weak-coupling barostat was 2 ps. Particle mesh Ewald method (PME) was used to treat long-range electrostatic interactions under periodic conditions with a direct space cutoff of $10 \AA$. The same cutoff was used for van der Waals interactions. In case of simulations in implicit solvent, the optimized GBn implicit solvent model $(\mathrm{ibg}=8)$ was used together with recommended Born radii set mbondi3. ${ }^{26}$ Infinite cutoff (cut $=9,999.0$ ) for nonbond interactions was used and temperature was controlled with Langevin thermostat. The pmemd.cuda module from Amber 14 package was used for all the above-described simulation steps. ${ }^{27}$ The last 10 nanoseconds of the whole simulation were used for energetic analyses (enthalpic contribution, $\mathrm{dH}$, calculated with 0.1 nanoseconds sampling step, ie, 100 frames used), entropic contribution (TdS) calculated using 3 nanoseconds sampling step (ie, four frames used) by using the molecular mechanics/Poisson-Boltzmann surface area methodology + normal mode analysis as implemented in Amber 14 routine MMPBSA.py to obtain estimates of free energies of binding. ${ }^{28}$ Poisson-Boltzmann surface area calculations were performed using Adaptive PoissonBoltzmann Solver sander. APBS from Amber 14. ${ }^{29}$ The probe radius used for calculation of solvent accessible surface area was $1.4 \AA$. Default Adaptive Poisson-Boltzmann Solver value $a=0.02508 \mathrm{kcal} / \mathrm{mol} / \mathrm{A}^{2}$ of cavity SURFTEN parameter for calculation of the nonpolar solvent contribution ENPOLAR $=a \times$ solvent accessible surface area was used.
The dielectric constant of the solute was set to 1 and in the case of solvent to 80 . Normal mode analysis was performed taking into account solvation using HCT generalized Born implicit solvation model. ${ }^{30}$ Single trajectory approach was used in this work.

\section{Dendrimer-antiviral combination analysis}

To evaluate the combined inhibitory effects of dendrimers and antivirals, such as ACV or TFV, on HSV-2 replication, the combination studies were performed using plaque reduction assays. Briefly, Vero cells were treated with various concentrations of the tested compounds or their combinations for 1 hour before HSV-2 infection with 150 FPU/well. After 2 hours, cells were washed and then covered with $2 \%$ FBS/DMEM containing human Ig and treated again with dendrimer alone or in combination with ACV at the same ratio. After 48 hours, Vero cells were then fixed and stained with metilen blue $0.4 \%$ for 1 hour and viral plaques were counted. The $50 \%, 75 \%$, and $90 \%$ effective concentrations $\left(\mathrm{EC}_{50}, \mathrm{EC}_{75}\right.$, and $\mathrm{EC}_{90}$, respectively) were determined, and synergism analysis was performed using the CalcuSyn software (Biosoft) based on the median effect principle. The CI values between 0.1 and 0.9 indicated a synergistic effect, whereas values between 0.9 and 1.1 represented an additive effect, and $>1.1$ represented antagonism.

\section{In vivo vaginal challenge assay}

G2-S16 and G1-S4 were selected for analyzing their inhibitory activity against $\mathrm{HSV}-2$ infection in BALB/c mice (Charles River Laboratories, Wilmington, MA, USA). Previously, we showed that both dendrimers did not induce vaginal irritation or inflammation in $\mathrm{BALB} / \mathrm{c}$ mice and they were well tolerated for topical application. ${ }^{8,17,31}$ Female $\mathrm{BALB} / \mathrm{c}$ mice $(20 \pm 2 \mathrm{~g})$ that were 6-8 weeks old were housed at the CBMSO. Animal studies were conducted and approved by the CBMSO Institutional Animal Care and Use Committee (CEEA-CBMSO, Madrid, Spain). An HEC (NIH-ARRRP) placebo gel was formulated by mixing HEC gel with sterile PBS to obtain a final concentration of $1 \%$ w/v. G2-S16 or G1-S4 was added to $1 \%$ HEC placebo gel to a final concentration of $3 \% \mathrm{w} / \mathrm{v}$. Prior to vaginal HSV-2 challenge, mice received a $2 \mathrm{mg}$ subcutaneous injection of medroxyprogesterone acetate (Depo-Provera [depo]; Pfizer, New York, NY, USA) to increase susceptibility to HSV-2 infection. ${ }^{32}$ Five days later, mice were anesthetized with isoflurane (2-chloro-2-(difluoromethoxy)-1,1,1-trifluoro-ethane; Forane, Abbott, Perú) for gel applications and HSV-2 infection. $\mathrm{BALB} / \mathrm{c}$ mice were randomized into four groups of ten mice; placebo group received $30 \mu \mathrm{L} \mathrm{1 \%} \mathrm{HEC} \mathrm{gel} \mathrm{vaginally,}$ 
G2-S16 group received 1\% HEC gel with 3\% G2-S16, G1-S4 group was treated with G1-S4 1\% HEC with 3\% G1-S4 and control group did not receive treatment. One hour later, mice were inoculated intravaginally with $10^{5} \mathrm{PFU} / 20 \mu \mathrm{L}$ of HSV- 2 and maintained in a supine position for 15 minutes postapplication.

Mice were examined daily for body weight and genital pathology over 16 days. Disease score was graded according to a 4-point scale: 0, no apparent infection; 1, genital erythema; 2 , moderate genital infection; 3 , purulent genital ulceration and hair loss, generally poor condition; and 4, severe ulceration of genital and surrounding tissue, and hind limb paralysis (leading to euthanasia).

\section{In vivo rectal challenge assay}

The rectal assays were performed by dissolving dendrimers in PBS. The experiment was conducted in female and male $\mathrm{BALB} / \mathrm{c}$ mice, five female and ten male mice per group (nontreated (NT), G1-S4 treated, and G2-S16 treated). Six to 8 -week-old mice were fasted for 24 hours before the rectal HSV- 2 challenge, but water complemented with $1 \%$ glucose was available ad libitum. Following initial infection, food and water were available ad libitum. Mice were anesthetized for both immobilizing them and preventing defecation using an intraperitoneal injection with Ketamine-Xylazine $(100 \mathrm{mg} / \mathrm{kg} / 10 \mathrm{mg} / \mathrm{kg})$ and randomized into three groups of five mice per group. Mice were treated with $25 \mu \mathrm{L}$ of test formulation, PBS 3\% G1-S4, PBS 3\% G2-S16, and PBS rectally with a gavage needle and maintained in a supine position with slight elevation of the pelvis for 30 minutes postapplication. Subsequently, $10^{5}$ PFU of HSV-2 diluted in PBS to a final volume $10 \mu \mathrm{L}$ was applied atraumatically to the rectum mucosa of anesthetized mice maintained in a supine position until they woke up. Moreover, two more rectal experiments with the same protocol were held; first one with 18 male mice (6 NT, $63 \%$ G2-S16 treated, and $63 \%$ G1-S4 treated) but increasing HSV-2 dose to $10^{6} \mathrm{PFU}$ for inoculation; second one with 12 mice ( 6 NT and $63 \%$ G2-S16 $+1 \%$ TFV treated). BALB/c mice were examined daily for body weight and genital pathology over 18 days. Disease score was evaluated as in the case of vaginal challenge assay.

\section{Statistical analysis}

Statistical analysis, including the calculation of the mean, standard deviation, and $P$-values, was performed using MannWhitney $U$ nonparametric test. The significance level was set as $P=0.05$. GraphPad Prism V6.0 software (San Diego, CA, USA) was used. All data were generated from duplicate or triplicate wells in at least three independent experiments.

\section{Results}

Screening of polyanionic carbosilane dendrimers antiviral activity against HSV-2

Several dendrimers showed a great anti-HIV-1 and antiHIV-2 activity against clinical viral strains. ${ }^{7-9,17}$ However, their ability to inhibit other sexually transmitted infections is unknown. In this work, antiviral activity against HSV-2 of eight dendrimers, which previously showed high anti-HIV activity were researched.

Toxicity assays were performed to evaluate the biocompatibility of dendrimers in Vero cells (Figure 1). Dendrimers concentrations with viability $>80 \%$ in comparison with control were regarded as nontoxic. G2-CTE16 was the most toxic, with a limit of viability of $0.1 \mu \mathrm{M}$. G3-S16 and G2-NF16 were nontoxic at $0.5 \mu \mathrm{M}$ and G2-S24P and G2-STE16 at $1 \mu \mathrm{M}$. G2-S16 was nontoxic at $10 \mu \mathrm{M}$ as previously reported in other cells. ${ }^{8}$ G1-C8 and G1-S4 were nontoxic at 5 and $10 \mu \mathrm{M}$, respectively.

Once nontoxic working concentrations for each dendrimer were established in vitro, a primary screening to test the ability of these dendrimers inhibiting HSV-2 infection in Vero cells was performed. Four of the studied dendrimers, G2-S16, G1-S4, G3-S16, and G2-STE16 inhibited significantly the HSV-2 (Figure 2A). We achieved 100\% anti-HSV-2 inhibitory activity when Vero cells were pretreated with 10 $\mu \mathrm{M}$ of G2-S16. G1-S4, G3-S16, and G2-STE16 dendrimers achieved a reduction of anti-HSV-2 activity of $77 \%, 68 \%$, and $28 \%$, respectively. G2-S16, G1-S4, and G3-S16 were chosen for a more detailed in vitro study.

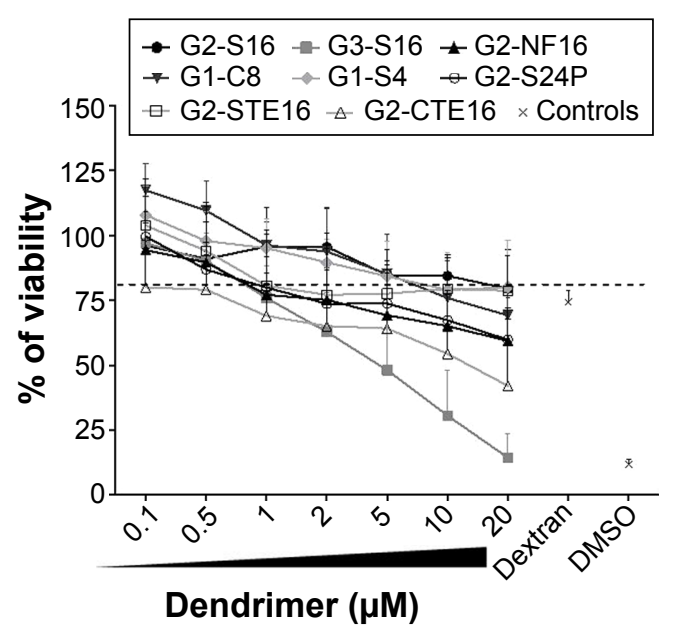

Figure I Biocompatibility of polyanionic carbosilane dendrimers in Vero cells. Notes: Viability of epithelial Vero cells was evaluated by MTT assay after 24 hours of exposure to a range of dendrimer concentrations; $80 \%$ of viability was set as the limit of toxicity for all dendrimers. Dextran $20 \mu \mathrm{M}$ and DMSO $10 \%$ were used as negative and positive control of cellular death, respectively. Data were represented as mean \pm standard deviation of three independent experiments.

Abbreviation: DMSO, dimethyl sulfoxide. 
A

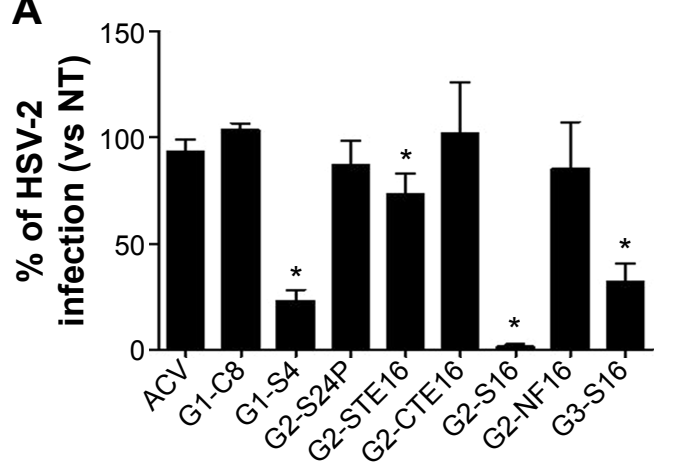

B

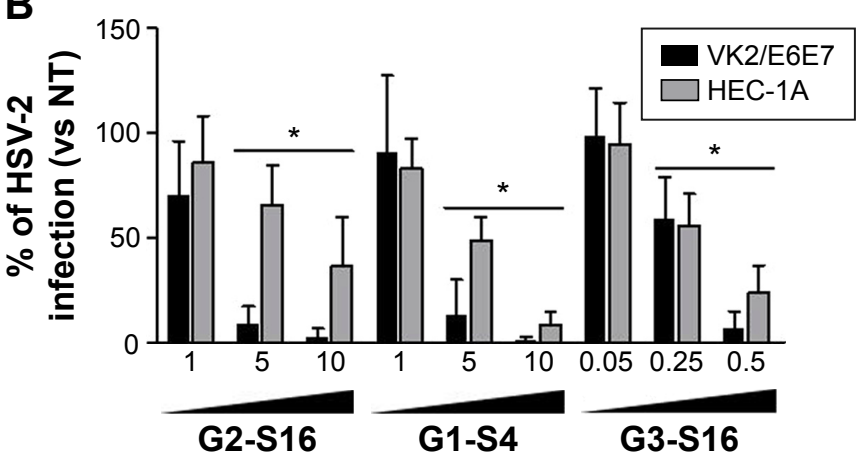

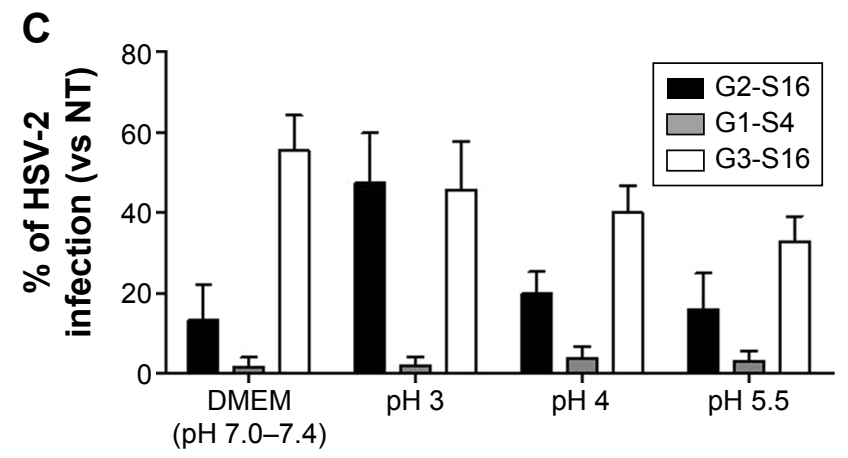

Figure 2 Dendrimers anti-HSV-2 activity.

Notes: (A) Primary screening of candidates inhibitory activity against HSV-2. Vero cells were pretreated with nontoxic concentrations of the compounds for I hour and then infected with HSV-2. Percentage of infection was determined after 48 hours. (B) Inhibition of HSV-2 by dendrimers in VK2/E6E7 and HEC-IA human epithelial cell lines. VK2/E6E7 or HEC-IA cells were treated with polyanionic dendrimers for I hour before infection with HSV-2. At 30-40 hours postinfection, supernatants were collected and their infectivity was assessed in a plaque reduction assay. (C) Effect of $\mathrm{pH}$ in dendrimer anti-HSV-2 activity. Tested dendrimers were incubated in different $\mathrm{pH}$ solutions

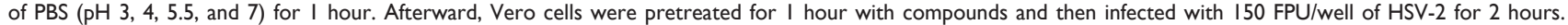
Viral infection, measured as number of viral plaques, was determined at 48 hours postinfection. Data were represented as mean \pm standard deviation of three independent experiments $(* \mathrm{P}<0.05$ vs control).

Abbreviations: ACV, acyclovir; DMEM, Dulbecco's Modified Eagle's Medium; HSV-2, herpes simplex virus type 2; NT, nontreated.

\section{Anti-HSV-2 activity of dendrimers in human genital tract epithelial cells}

We studied the antiviral activity of G2-S16, G1-S4, and G3-S16 selected dendrimers in HEC-1A and VK2/E6E7, human epithelial cell lines (Figure 2B). When HEC-1A and VK2/E6E7 were pretreated with $10 \mu \mathrm{M}$ of G2-S16, the HSV-2 inhibition was $68 \%$ and $98 \%$, respectively and when pretreated with G1-S4 at $10 \mu \mathrm{M}$, the HSV-2 inhibition was $92 \%$ and $99 \%$, respectively. Finally, a decrease of $72 \%$ and 94\% of HSV-2 infection was achieved in HEC-1A and VK2/ E6E7 cells when pretreated with G3-S16 at $0.5 \mu \mathrm{M}$. In conclusion, dendrimers were highly effective in inhibiting the infection of HSV-2 in both epithelial cell lines.

\section{Antiherpetic efficacy of dendrimers at various $\mathrm{pH}$}

One critical point to develop microbicidal compounds is to evaluate their stability and biological activity during the critical change of vaginal $\mathrm{pH}$ from 4.5 to 7.0 , which occurs at the time of ejaculation. ${ }^{33} \mathrm{G} 2-\mathrm{S} 16, \mathrm{G} 1-\mathrm{S} 4$, or G3-S16 was incubated in $\mathrm{pH}$ solutions from 3.0 to 7.0. Afterward, Vero cells were pretreated with these solutions of each dendrimer and infected with HSV-2. The three dendrimers retained their activity against HSV-2 after incubation at $\mathrm{pH}$ from 3 to 7 for 1 hour (Figure 2C).

\section{Evaluation of the mechanism of dendrimers' anti-HSV-2 action}

To determine the stage of the HSV-2 lifecycle where G2-S16, G1-S4, or G3-S16 dendrimers act, a time-of-addition assay was performed (Figure 3A). Acyclovir (ACV) was used as control. Very strong inhibition of HSV-2 infection was only found when G2-S16, G1-S4, or G3-S16 was added as a pretreatment or one hour postinfection (pi). It is important to note that the dendrimers G1-S4 and G3-S16 lost their inhibitory action when added at one hour pi. However, in case of G2-S16, approximately $50 \%$ of anti-HSV-2 activity was retained when added at 8 hours pi. In conclusion, 

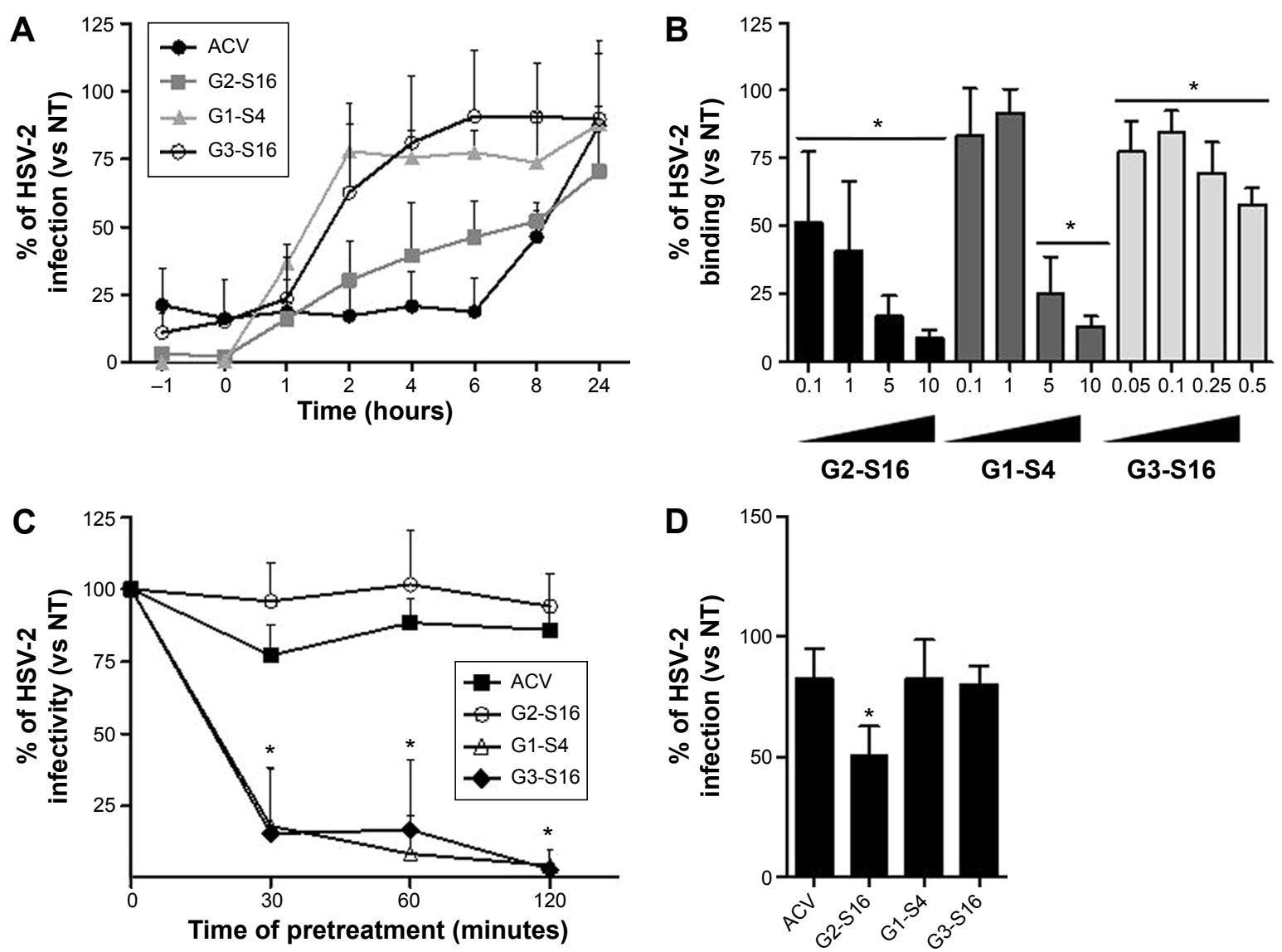

Figure 3 Mode of action of polyanionic carbosilane dendrimers against HSV-2 infection.

Notes: (A) Time of addition assay. To establish the stage of viral cycle where dendrimers are acting, Vero cells were infected with HSV-2 and dendrimers were added at $0,1,2,4,6,8$, and 24 hours postinfection. Percentage of infection was determined after 48 hours. (B) Effect of anionic dendrimers on HSV-2 binding. Vero cells were prechilled at $4^{\circ} \mathrm{C}$ for 20 minutes and then treated with the dendrimers for I hour before infection with HSV-2 for 2 hours at $4^{\circ} \mathrm{C}$. (C) HSV-2 inactivation by dendrimers. To test the ability of dendrimers to bind to the viral surface, $10^{4} \mathrm{FPU}$ of HSV-2 were incubated with the dendrimers at their maximum nontoxic concentration for I hour. Vero cells were then infected with $150 \mathrm{FPU} /$ well of dendrimer-treated HSV-2. Viral infectivity, measured as number of viral plaques, was determined at 48 hours postinfection. (D) Binding of dendrimers to cellular surface proteins. Vero cells were pretreated with dendrimers for I hour. After incubation, cells were washed to eliminate unbound dendrimer and then infected with HSV-2. After 48 hours, cells were stained and viral plaques were counted. Data were represented as mean \pm standard deviation of three independent experiments ( $* P<0.05$ vs control).

Abbreviations: ACV, acyclovir; HSV-2, herpes simplex virus type 2; NT, nontreated.

the role of these dendrimers is in the very first steps of the HSV-2 lifecycle, except for G2-S16 that, in addition, has other secondary targeting levels.

The antiviral activity of polyanionic dendrimers is associated with the establishment of electrostatic interactions between the viral envelope proteins and the anionic functional peripheral groups of dendrimers. ${ }^{8,14,15,17}$ The effect of polyanionic dendrimers in HSV-2 binding was studied (Figure 3B). The attachment of HSV-2 to Vero cells was inhibited in a doseresponse effect by the three dendrimers (Figure 3B). G2-S16, G1-S4, and G3-S16 achieved $91 \%, 87 \%$, and $42 \%$ of reduction of HSV-2 binding in Vero cells, respectively, in comparison with HSV-2-infected nontreated Vero cells (Figure 3B).

We studied how dendrimers performed their antiviral activity by using a virus inactivation assay (Figure 3C). G1-S4 and G3-S16 inhibited HSV-2 infection in Vero cells approximately $85 \%$ after 30 minutes of coincubation with HSV-2, and viral inactivation was complete after 2 hours of coincubation. Our results suggest that G1-S4 and G3-S16 bind directly on viral proteins at the surface of HSV-2 and block and inactivate HSV-2, and G2-S16 is ineffective in reducing HSV-2 infectivity (Figure 3C). Thus, one assay was performed to evaluate the binding ability of G2-S16, G1-S4, or G3-S16 onto cellular surface proteins and, therefore, block the HSV-2 attachment and entry (Figure 3D). After incubation of G2-S16, G1-S4, or G3-S16 with Vero cells, only the G2-S16 reduced 50\% the HSV-2 infection. G2-S16, unlike G1-S4 and G3-S16, was performing its inhibitory effect by binding to molecules on the surface of host cell. In conclusion, G1-S4 and G3-S16 bind to HSV-2 to perform their antiherpetic activity, whereas G2-S16 does it by binding to the cellular surface of molecules in host cell. 


\section{Modeling the interactions of dendrimers with HSV-2 surface protein gB}

We focused on G2-S16 and G1-S4 for molecular modeling studies due to the fact that these dendrimers caused the maximum reduction of HSV-2 binding in Vero cells. The fusion protein $\mathrm{gB}$ is one of the most conserved in the HSV-2 surface. It, together with the help of the fusion regulator $\mathrm{gH}-\mathrm{gL}$ and receptor binding $\mathrm{gD}$, mediates $\mathrm{HSV}-2 /$ cell fusion. We used computer simulations to study whether G1-S4 and G2-S16 bind the gB from HSV-2 and the differences in binding modes of both dendrimers ${ }^{22}$ (Figure S5A and B). The simulation test of dendrimer $/ \mathrm{gB}$ complexation at six binding sites on $\mathrm{gB}$ surface showed the creation of stable complexes in all cases (Figures $4, \underline{\mathrm{S} 6}$ ). The binding energies $\mathrm{dG}$ and their components are summarized in Table 1. The domains $\mathrm{A}$ and $\mathrm{B}$ are the binding area for the interaction with heterodimer $\mathrm{gH}-\mathrm{gL}$ (Figure $\mathrm{S} 7 \mathrm{~A}$ and $\mathrm{B}$ ). ${ }^{34}$ It is a cationic area suitable for binding of both anionic dendrimers as shown in Table 1. The G1-S4 binding affinity was clearly better than the G2-S16 binding affinity. Case C represents the binding area to the putative fusion loops or their proximity. Although binding energies were smaller than in cases A and B, the G1-S4 anionic dendrimer was slightly better than G2-S16. However, the G2-S16 anionic dendrimer interacted directly with fusion loops, whereas the G1-S4 interacted partly with fusion loops and partly with simulated C-terminal (Figure S7C). Above the fusion loops there is cationic area so the another potential binding interface for anionic molecules - case D. (Figure S7D). G2-S16 provided here the worst result among all the tested binding positions. The dendrimer bound in position D may have the best possibility to disturb the suggested transition of the $\mathrm{gB}$ trimeric state from the more open prefusion to the final closed postfusion (Figure S8). ${ }^{34}$ Both anionic dendrimers partially interact with $\mathrm{C}$-terminal of the given $\mathrm{gB}$, which is not possible in the $\mathrm{gB}$ trimeric state since the $\mathrm{C}$-terminal part of the given $\mathrm{gB}$ monomer is located too far from its $\mathrm{D}$ position. However, both dendrimers interact very similarly with C-terminal of the opposite gB monomer (Figure S8). Simulation case $\mathrm{E}$ is an anionic area with a "pocket" shape character composed of the top-inner edge of $\mathrm{gH}-\mathrm{gL}$ binding interface (Figures S5A, B and S7E). The electrostatic interaction of G2-S16 and G1-S4 with protein in vacuum conditions is unfavorable for both dendrimers, but in water this is compensated by the energy contribution from the electrostatic interactions of solvated molecules. Thus, stable complexes
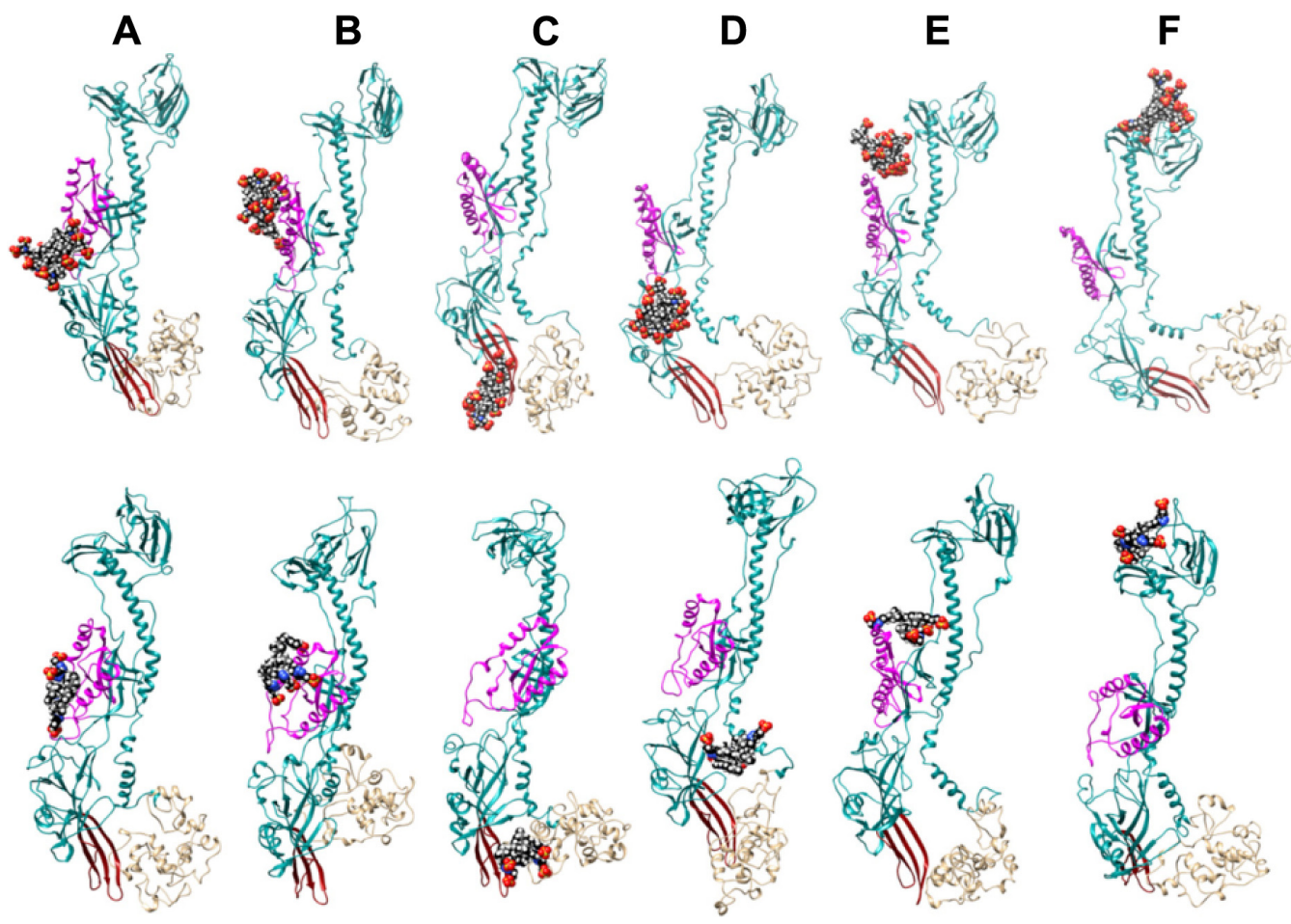

Figure 4 Final G2-SI6/gB (top) and GI-S4/gB (bottom) complexes obtained from the initial configurations (A-F) - see Supplementary materials.

Notes: The main part of the supposed binding interface for the $\mathrm{gH}-\mathrm{gL}$ is highlighted in magenta. The putative fusion loops are in red and the $\mathrm{C}$-terminal part comprising residues 722-904 is in tan. This terminal part of the $\mathrm{gB}$ was not included in our template structure (4BOM), Therefore, we simulated it from the primary amino acid sequence just to "naturally" close this incomplete part. In reality, most of this gB part anchored in viral membrane has different tertiary structure. Atoms of dendrimers are colored as follows: C, black; O, red; Si, gray; S, yellow; N, blue; H, white. 
Table I MM-PBSA estimates of free energies of binding (dG) together with all important energetic components and numbers of dendrimer/protein $\mathrm{H}$-bonds detected in final configurations

\begin{tabular}{|c|c|c|c|c|c|c|c|c|}
\hline Dendrimer & dH & TdS & dG & VDW & EEL & EPB & ENP & H-bonds \\
\hline \multirow[t]{2}{*}{ G2_SI6 (A) } & -106.78 & -46.70 & -60.08 & -59.03 & -526.49 & 516.57 & -37.83 & 21 \\
\hline & $(26.15)$ & $(9.30)$ & (27.76) & $(14.15)$ & $(130.25)$ & (I29.77) & (7.82) & \\
\hline \multirow[t]{2}{*}{ G2_SI6 (B) } & -109.21 & -50.57 & -58.64 & -71.34 & -343.05 & 345.61 & -40.43 & 11 \\
\hline & $(19.36)$ & (II.I7) & $(22.35)$ & $(7.13)$ & (70.77) & $(69.53)$ & $(2.02)$ & \\
\hline \multirow[t]{2}{*}{ G2_SI6 (C) } & -101.43 & -47.45 & -53.97 & -62.41 & 117.49 & -119.16 & -37.34 & 7 \\
\hline & $(20.43)$ & $(8.99)$ & $(22.32)$ & $(6.91)$ & $(\mid 37.20)$ & (137.33) & $(3.62)$ & \\
\hline \multirow[t]{2}{*}{ G2_SI6 (D) } & -70.98 & -50.09 & -20.89 & $-4|.5|$ & -341.54 & 340.26 & -28.19 & 15 \\
\hline & (17.53) & (7.08) & $(18.90)$ & (7.58) & $(66.61)$ & $(68.62)$ & (3.99) & \\
\hline \multirow[t]{2}{*}{ G2_SI6 (E) } & -66.65 & -42.12 & -24.54 & -36.58 & 297.45 & -299.85 & -27.67 & 11 \\
\hline & $(22.11)$ & $(10.18)$ & (24.34) & $(5.73)$ & $(92.03)$ & $(95.06)$ & $(2.42)$ & \\
\hline \multirow[t]{2}{*}{ G2_SI6 (F) } & -151.57 & -60.13 & -91.44 & -89.16 & -413.22 & 402.39 & -51.58 & 19 \\
\hline & $(21.33)$ & $(12.62)$ & (24.79) & $(7.83)$ & $(67.98)$ & $(69.24)$ & $(2.11)$ & \\
\hline G2_SI6 & $-|40.6|$ & -64.97 & -75.65 & -74.32 & $-3,682.17$ & $3,663.67$ & -47.80 & 22 \\
\hline (N-term) & $(10.98)$ & $(5.60)$ & $(12.33)$ & $(5.77)$ & $(170.52)$ & $(169.95)$ & $(2.65)$ & \\
\hline \multirow[t]{2}{*}{ GI_S4 (A) } & -120.80 & -45.54 & -75.26 & -74.92 & -269.87 & 265.27 & -41.28 & 7 \\
\hline & $(8.49)$ & $(4.34)$ & $(9.54)$ & $(6.55)$ & (44.99) & (44.09) & $(2.19)$ & \\
\hline \multirow[t]{2}{*}{ GI_S4 (B) } & -113.17 & -43.17 & -70.01 & -73.5 I & -188.86 & $186.8 \mid$ & -37.61 & 6 \\
\hline & $(12.74)$ & (II.74) & $(17.32)$ & $(9.5 \mathrm{I})$ & $(40.40)$ & (39.35) & $(2.97)$ & \\
\hline \multirow[t]{2}{*}{ GI_S4 (C) } & -100.13 & -41.24 & -58.88 & $-63.5 I$ & -197.97 & 196.96 & -35.61 & 5 \\
\hline & (I2.99) & $(5.45)$ & (14.08) & $(9.33)$ & $(63.33)$ & $(62.63)$ & (3.58) & \\
\hline \multirow[t]{2}{*}{ GI_S4 (D) } & -88.92 & -34.52 & -54.40 & -55.02 & -246.20 & 242.40 & -30.10 & 6 \\
\hline & $(8.28)$ & $(9.66)$ & $(12.73)$ & $(6.01)$ & $(46.48)$ & (45.52) & $(2.76)$ & \\
\hline \multirow[t]{2}{*}{ GI_S4 (E) } & -104.28 & -45.43 & -58.85 & -65.73 & 20.09 & -21.39 & -37.25 & 6 \\
\hline & $(10.37)$ & (7.08) & $(12.56)$ & $(7.48)$ & $(30.60)$ & $(30.10)$ & (3.23) & \\
\hline \multirow[t]{2}{*}{ GI_S4 (F) } & -126.48 & -44.02 & -82.46 & -81.21 & -190.90 & 188.06 & -42.43 & 5 \\
\hline & $(8.64)$ & $(4.16)$ & (9.59) & $(5.78)$ & $(35.65)$ & $(36.18)$ & (I.7I) & \\
\hline GI_S4 & -99.86 & -38.60 & -61.27 & -58.89 & $-1,321.18$ & $1,311.29$ & -31.09 & 9 \\
\hline$(\mathrm{N}$-term) & $(8.50)$ & $(2.08)$ & (12.33) & $(5.21)$ & $(54.82)$ & $(54.22)$ & (1.58) & \\
\hline
\end{tabular}

Notes: The units are in $\mathrm{kcal} / \mathrm{mol}$. $\mathrm{dH}=\mathrm{VDW}+\mathrm{EEL}+\mathrm{EPB}+\mathrm{ENPOLAR}, \mathrm{dG}=\mathrm{dH}-\mathrm{TdS}$. Values of $\mathrm{dH}$ and TdS were not calculated from the identical MD frames so the standard deviation for $\mathrm{dG}$ obtained from the population of $\mathrm{dH}-\mathrm{TdS}$ values are not available. Instead, the square root of the sum of squares of the standard deviations for $\mathrm{dH}$ and TdS is provided as the upper bound estimate for dG deviation. The significance of the bold values are the total enthalpic contribution to free binding energy deviation. Abbreviations: $\mathrm{dH}$, total enthalpic contribution to free binding energy; $\mathrm{dS}$, solute entropy change due to binding; EEL, electrostatic contribution in vacuum (ie, without considering solvent); ENP, estimate for nonpolar contribution; EPB, energetic contribution that arises from electrostatic solvent-solute interaction (desolvation penalty); MD, molecular dynamics; MM/PBSA, molecular mechanics/Poisson-Boltzmann surface area; T, absolute temperature; VDW, van der Waals contribution to binding enthalpy.

were obtained in both cases. G1-S4 binds here with significantly higher affinity $\mathrm{dG}=-58.85 \mathrm{kcal} / \mathrm{mol}$ (Table 1 ), mainly due to the more significantly favorable van der Waals component $-65.73 \mathrm{kcal} / \mathrm{mol}$ than $-36.58 \mathrm{kcal} / \mathrm{mol}$ in the case of G2-S16. This result is due to the small and flexible G1-S4 with better accessible "uncharged" C-Si inner part. Moreover, G1-S4 with smaller anionic charge better accommodates in the pocket site and has more "van der Waals contacts" with protein than G2-S16. G1-S4 has also a more favorable estimate for nonpolar contribution part, which means that the complexation reduced the total (dendrimer $+\mathrm{gB}$ ) solvent accessible molecular surface better than in the case of bigger dendrimer.

Surprisingly, strong binding affinity was found in simulation case $\mathrm{F}$, where dendrimers interacted with the top part of the protein (Figure S7F). Both dendrimers achieved here their best results regarding binding energy. It was the only case where $\mathrm{G} 2-\mathrm{S} 16$ ( $\mathrm{dG}=-91.44 \mathrm{kcal} / \mathrm{mol})$ overperformed G1-S4 (dG $=-82.46 \mathrm{kcal} / \mathrm{mol}$ ) (Figure S9). Unfortunately, the N-terminal end of our $\mathrm{gB}$ structure is incomplete, having the first 97 aa missing. The experimental structure of this $\mathrm{gB}$ $\mathrm{N}$-terminus part from HSV-2 is not at disposal. We simulated $\mathrm{N}$-terminus fragment comprising $1-100$ aa to obtain its approximate tertiary structure (Figure S10) and to check if this part can be targeted with dendrimers or if position $\mathrm{F}$ is the only suitable dendrimer-binding site in $\mathrm{N}$-terminus area. This small terminal part has a quite cationic character (the total net charge +12 ) and can serve as an attractive target for any anionic molecules (Figure S10). Thus, HSV-2 gB can interact with anionic cell glycosaminoglycans like heparan sulfate. This N-terminal part is attractive for our G1-S4 and G2-16 anionic dendrimers (Figure S11 and Table 1). G2-S16 binds 
with higher affinity $(\mathrm{dG}=-75.65)$ to this $\mathrm{N}$-terminal target than $\mathrm{G} 1-\mathrm{S} 4(\mathrm{dG}=-61.27)$ similarly as in position F.

\section{Increased efficiency of dendrimer/ antiviral drug combination}

Since polyanionic carbosilane dendrimers seem to target different steps in viral life cycle in comparison with other antivirals such as ACV and tenofovir (TFV), the potential combinatorial profile of dendrimer and ACV or dendrimer and TFV was tested against HSV-2. Interestingly, the nucleoside reverse-transcriptase inhibitor TFV is the only microbicide candidate, which shows high efficacy to date. Neither the combinations nor the individual drug concentrations were toxic for Vero cells after 24 hours of exposure (data not shown). The combinations of G2-S16, G1-S4, and G3-S16 dendrimers with ACV or TFV resulted in a more efficient inhibitory profile against HSV-2 for most of the concentrations tested, measured as viral plaque formation (Figure S12).

In addition, the combination indexes $(\mathrm{CI})$ were calculated to evaluate the type of dendrimer-ACV or dendrimerTFV interactions (Table 2). CalcuSyn software (Biosoft, Cambridge, UK) based on the median effect principle was used. The CI values between 0.1 and 0.9 indicate a synergistic effect, whereas values between 0.9 and 1.1 represent an additive effect, and those $>1.1$ represent antagonism. Synergistic profiles (CI values between 0.442 and 0.705 ) were found at the calculated $\mathrm{EC}_{75}$ and $\mathrm{EC}_{90}$ for $\mathrm{G} 2-\mathrm{S} 16$ and $\mathrm{G} 1-\mathrm{S} 4$ when combined with ACV against HSV-2. G3-S16/ACV combination at 1:10 ratio showed slight and moderate synergism at the $\mathrm{EC}_{50}$ and $\mathrm{EC}_{75}$, respectively, although only an additive effect was found at high concentrations $\left(\mathrm{EC}_{90}\right)$. All dendrimers showed a synergistic profile with $\mathrm{TFV}$ at $\mathrm{EC}_{90}$. However, nonpositive interactions or only an additive profile for G1-S4 dendrimer were found at the calculated $\mathrm{EC}_{50}$. These results support that the combinations of nanoplatforms like dendrimers and other inhibitory drugs targeting different stages in virus life cycle are essential to develop more powerful and effective microbicides and to improve the existing ones.

\section{Antiherpetic activity of dendrimers, vaginal challenge}

This study was carried out to demonstrate the in vivo efficacy of topical G2-S16 and G1-S4 to prevent vaginal HSV-2 transmission. G2-S16 and G1-S4 proved capable to halt the infection in $100 \%$ and $90 \%$ of female mice, respectively, upon exposure to a lethal dose of HSV-2, showing significant differences compared with control and placebo groups (G2-S16 $P=0.0003$ vs placebo) $(\mathrm{G} 1-\mathrm{S} 4 P=0.001$ vs placebo) (Figure 5A). The weight of female mice in control and placebo groups decreased steadily from day $6 \mathrm{pi}$. BALB/c groups treated with G2-S16 or G1-S4 body weight maintained its normal growth ratio (Figure 5B). No female mice treated with G2-S16 showed signs of HSV-2 infection and only one female mouse treated with G1-S4 showed signs of HSV-2 infection. Accordingly, untreated BALB/c female mice and those just treated with placebo started showing the first signs of redness and inflammation on day 3 pi, increasing the symptomatology until the moment of sacrifice between days 8 and 16 pi. (Figure 5C).

Table 2 Combination index ( \pm standard deviation) and combinatorial profiles for different antiretrovirals (ACV and TFV) and G2-SI6, GI-S4, and G3-SI 6 dendrimer combinations at equipotent ratio against HSV-2 strain 333 isolate in Vero cells

\begin{tabular}{|c|c|c|c|c|c|}
\hline \multirow[t]{2}{*}{ Dendrimer } & \multirow[t]{2}{*}{ ARV } & \multirow{2}{*}{$\begin{array}{l}\text { Combination } \\
\text { ratio }\end{array}$} & \multicolumn{3}{|l|}{$\mathrm{Cl}$} \\
\hline & & & $\mathrm{EC}_{50}$ & $\mathrm{EC}_{75}$ & $E C_{90}$ \\
\hline \multirow[t]{4}{*}{ G2-SI6 } & $\mathrm{ACV}$ & $1: 1$ & $1.055 \pm 0.122$ & $0.705 \pm 0.053$ & $0.528 \pm 0.041$ \\
\hline & & & $( \pm)$ & $(++)$ & $(+++)$ \\
\hline & TFV & I:I & $1.305 \pm 1.147$ & $1.013 \pm 0.702$ & $0.843 \pm 0.455$ \\
\hline & & & $(-)$ & $( \pm)$ & $(++)$ \\
\hline \multirow[t]{4}{*}{ GI-S4 } & $\mathrm{ACV}$ & $1: 1$ & $0.912 \pm 0.103$ & $0.616 \pm 0.139$ & $0.442 \pm 0.146$ \\
\hline & & & $( \pm)$ & $(+++)$ & $(+++)$ \\
\hline & TFV & I:I & $0.976 \pm 0.244$ & $0.826 \pm 0.282$ & $0.754 \pm 0.315$ \\
\hline & & & $( \pm)$ & $(++)$ & $(++)$ \\
\hline \multirow[t]{4}{*}{ G3-SI6 } & $\mathrm{ACV}$ & $1: 10$ & $0.852 \pm 0.160$ & $0.767 \pm 0.23$ | & $0.911 \pm 0.596$ \\
\hline & & & $(+)$ & $(+)$ & $( \pm)$ \\
\hline & TFV & $\mathrm{I}: 20$ & $1.108 \pm 0.415$ & $0.792 \pm 0.369$ & $0.597 \pm 0.286$ \\
\hline & & & $(-)$ & $(++)$ & $(+++)$ \\
\hline
\end{tabular}

Notes: $\mathrm{Cl}$ calculated at the $\mathrm{EC}_{50}, \mathrm{EC}_{75}$, and $\mathrm{EC}_{90}$ level. $\mathrm{Cl}<0.9$ indicates synergism; $0.9<\mathrm{Cl}<\mathrm{I}$.I indicates additive effects, and $\mathrm{Cl}>\mathrm{I}$.I indicates antagonism (-). Synergy level: $0.85<\mathrm{Cl}<0.9+$ (slight synergism); $0.7<\mathrm{Cl}<0.85++$ (moderate synergism); $0.3<\mathrm{Cl}<0.7+++$ (synergism). None of the results have the values of $0.1<\mathrm{Cl}<0.3++++$ (potent synergism); $0.1>\mathrm{Cl}+++++$ (very strong synergism). Data are represented as mean \pm standard deviation of three independent experiments.

Abbreviations: ACV, acyclovir; ARV, antiretroviral; $\mathrm{Cl}$, combination index; TFV, tenofovir. 

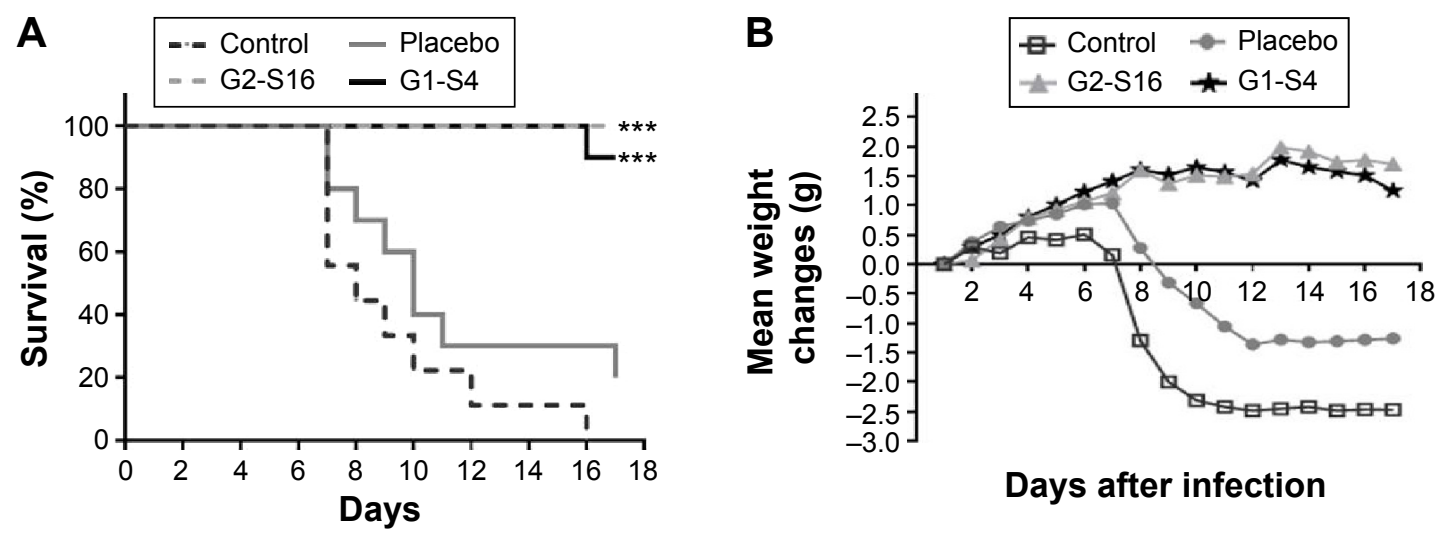

Days after infection

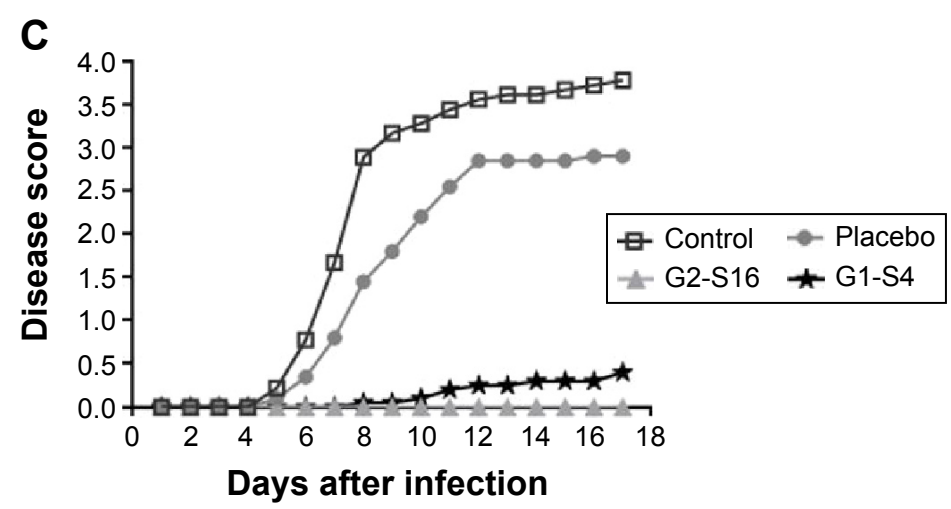

Figure 5 Polyanionic carbosilane dendrimers prevent vaginal high-dose HSV-2 infection.

Notes: Medroxyprogesterone acetate-treated BALB/c mice were vaginally challenged with $10^{5}$ PFU HSV-2 I hour after applying the indicated gel (I0 mice/group). Mice were examined daily for body weight and genital pathology over 16 days. (A) Percentages of infection over time are shown for each treatment group. Dendrimer-based gels containing $3 \%$ dendrimer were significantly more protective than vehicle alone (***P $<0.00 \mathrm{I}$ vs placebo). (B) Body weight changes were expressed as the mean values of ten animals in the same group. Each mean value was calculated by subtracting the weight at day 0 from the weight at day $\mathrm{N}$ after infection. (C) Clinical pathology was scored as described in the text for 16 days. Lesion scores were expressed as the mean values of ten mice in the same group.

Abbreviations: HSV-2, herpes simplex virus type 2; PFU, plaque-forming units.

\section{Antiherpetic activity of dendrimers: rectal challenge}

This work was performed to show the in vivo efficacy of topical G2-S16 and G1-S4 to prevent rectal HSV-2 transmission. The experiments were conducted in the rectum of male and female BALB/c mice separately, using $15 \mathrm{BALB} / \mathrm{c}$ mice for each sex. Five females and ten males were pretreated only with phosphate-buffered saline (PBS), five females and ten males were pretreated with PBS 3\% G2-S16, and five females and ten males were pretreated with PBS 3\% G1-S4 rectally. As expected, when we compare the antiherpetic activity obtained in both sexes, no significant differences were found (Figure S13). Thus, we put together the rectal results of both experiments, with $45 \mathrm{BALB} / \mathrm{c}$ mice (15 control received topical PBS, 15 PBS with 3\% G2-S16, and 15 PBS with $3 \%$ G1-S4) that were exposed to HSV-2. Four out of 15 mice of the PBS control group were not HSV-2 infected, while 7 out of 15 of G2-S16-treated group and 14 out of 15 of G1-S4-treated group were protected. G2-S16 was unable to stop the rectal infection in a significant way, but
G1-S4 reached inhibition rectal values over 90\% (Figure 6A), showing significant differences ( $P<0.0001$ vs control).

The antiherpetic activity of G1-S4 and G2-S16 was smaller in the case of rectal HSV-2 exposure than for vaginal exposure, leading to a faster appearance of the symptoms and death of the animals. Despite this, we observed a significant decrease in body weight in the control group and the G2-S16treated group, while mice rectal pretreated with G1-S4 maintained their normal body growth ratio (Figure 6B). Only one mouse pretreated with G1-S4 rectally showed signs of HSV-2 infection. Untreated BALB/c mice started showing first signs of redness and inflammation on day 5 pi, increasing the symptomatology until the moment of sacrifice between days 6 and 18 pi. (Figure 6C).

In order to confirm antiherpetic activity of G1-S4, we performed the viral challenge by using $10^{6}$ plaque-forming units (PFU) of HSV-2 per mouse. At such a high viral challenge, we demonstrated that G1-S4 increased the inhibition of HSV-2 rectal infection in BALB/c mice by $90 \%(P<0.0001$ vs control) (Figure S14). 
A
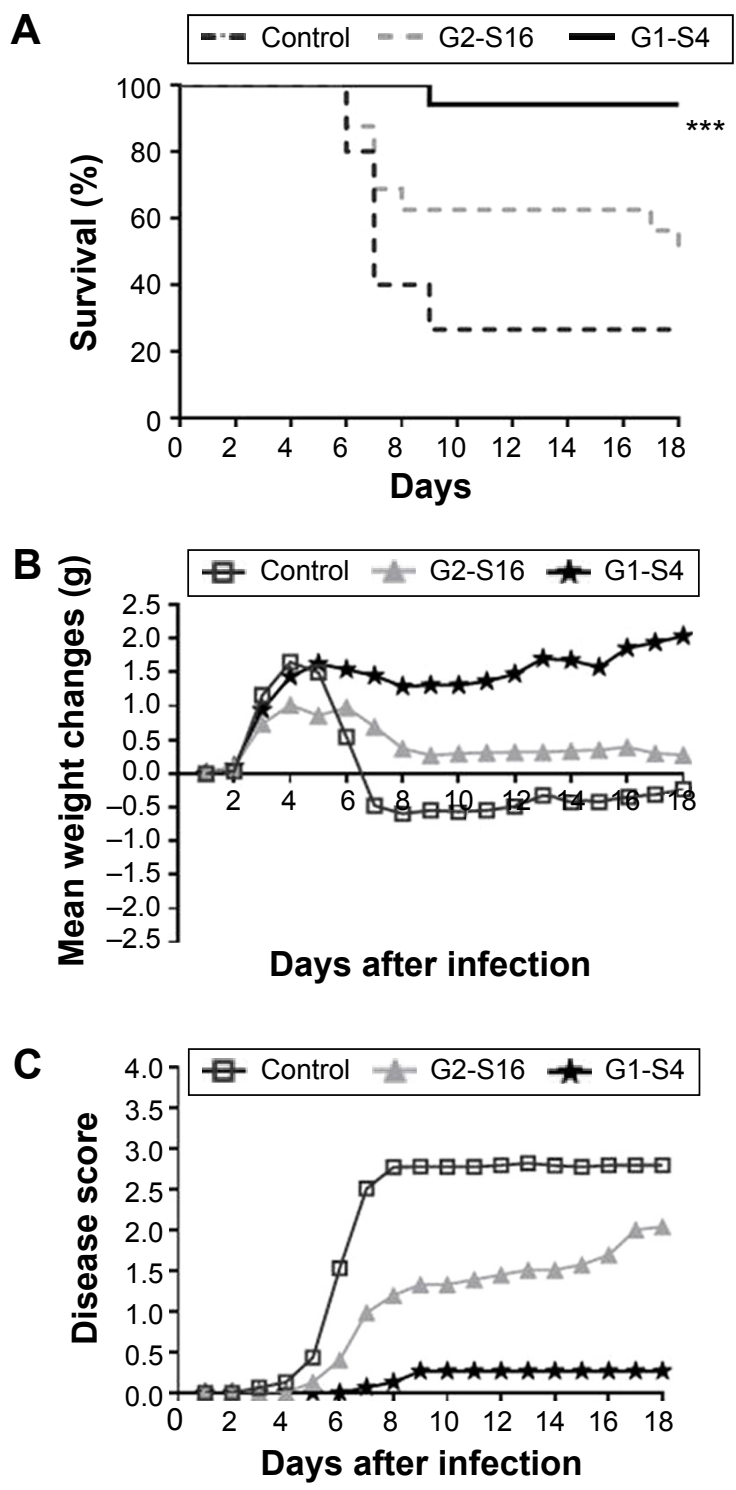

D

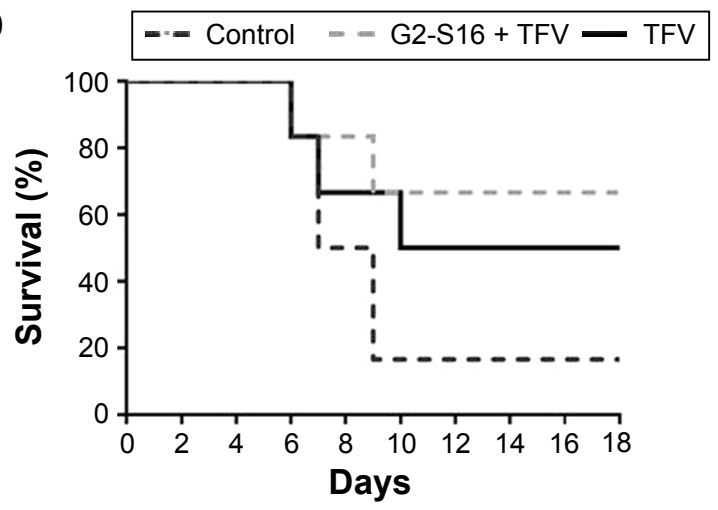

E

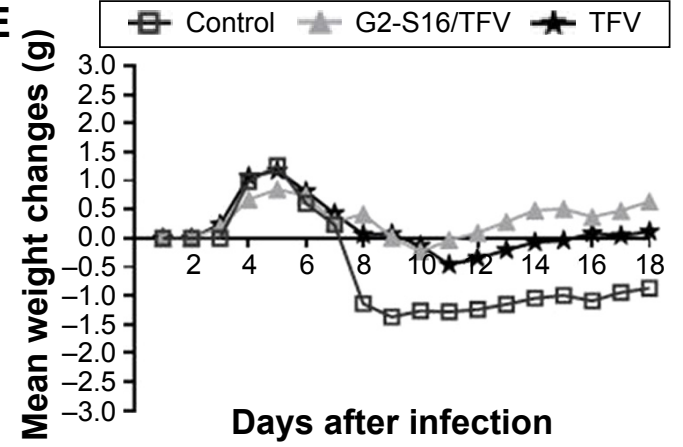

$\mathbf{F}$

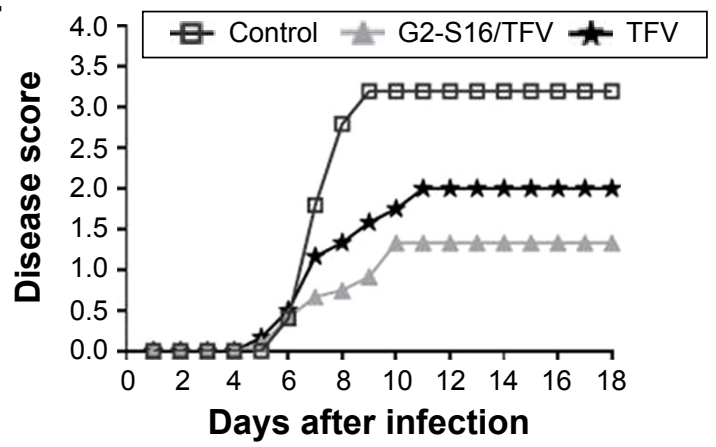

Figure 6 Polyanionic carbosilane dendrimers prevent rectal high-dose HSV-2 infection.

Notes: BALB/c mice were rectally challenged with $10^{5}$ PFU HSV-2 30 minutes after applying the indicated gel (I5 mice/group). Mice were examined daily for body weight and genital pathology over 18 days. (A and D) The percentages of infection over time, based on symptoms, are shown for each treatment group. GI-S4 was significantly protective (***P $<0.005$ vs control). (B and $\mathbf{E}$ ) Body weight changes were expressed as the mean values of ten mice in the same group. Each mean value was calculated by subtracting the weight at day 0 from the weight at day $\mathrm{N}$ after infection. ( $\mathbf{C}$ and $\mathbf{F}$ ) Clinical pathology was scored as described in the text for 18 days. Lesion scores were expressed as the mean values of ten mice in the same group. See also Figures S9 and $\underline{\text { II }}$.

Abbreviations: HSV-2, herpes simplex virus type 2; PFU, plaque-forming units; TFV, tenofovir.

To improve the protection values obtained with G2-S16 against rectal HSV-2 infection and due to the good results obtained with this dendrimer in combination with TFV, we performed another rectal challenge assay to evaluate a combination of $3 \% \mathrm{G} 2-\mathrm{S} 16$ and $1 \% \mathrm{TFV}$, demonstrating that this combination was able to increase the protection levels over 65\% (Figure 6D-F).

\section{Discussion}

Genital herpes is the STI with the highest global prevalence and appears frequently associated with other infections. ${ }^{35}$ Epidemiological studies suggest that HSV-2 increases the risk of HIV-1 acquisition by approximately threefold. ${ }^{2}$ This risk could be even higher in those with newly acquired HSV-2 infection. Among people infected with HIV-1, HSV-2 infection increases transmissibility of HIV-1 up to fivefold through genital ulcer and may accelerate the development to AIDS. ${ }^{1}$ In populations with high HSV-2 prevalence, approximately $50 \%$ of HIV- 1 infections are attributable to HSV-2 coinfection. Therefore, HSV-2 infection is an important cofactor in the HIV-1 transmission; this highlights the need for a safe and effective user-controlled strategy to prevent this infection. ${ }^{1}$ Consistent with this, polyanionic carbosilane dendrimers could be great candidates for the 
development of an anti-HSV-2 microbicide due to their synthesis, structure, molecular modeling, and their mode of antiviral action. ${ }^{8,14,17,36}$

We performed a screening of eight selected polyanionic dendrimers that previously demonstrated anti-HIV-1 activity in vitro and in vivo ${ }^{11}$ to select proper candidates for the development of a topical microbicide against HSV-2 infection. Plaque reduction assay showed that G1-S4, G2-S16, and G3-S16 have strong antiviral activity against HSV-2 in vitro by inhibiting HSV-2 binding and internalization into the Vero cells. Time of addition assay demonstrated strong inhibition of HSV-2 infection when dendrimers were added at the first hour after HSV-2 infection, indicating that dendrimers act at early phases of the HSV-2 lifecycle. The fact that G2-S16 is able to keep its inhibitory effect close to $50 \% 8$ hours pi suggests that it acts both at the early and late stages of the HSV-2 life cycle.

HSV-2 gB plays an important role in HSV-2 entry by binding to cell-surface heparan sulfate. ${ }^{37} \mathrm{G} 1-\mathrm{S} 4$ and G3-S16 have sulfate groups on their surface, which lead to the hypothesis that our dendrimers could bind to HSV-2 $\mathrm{gB}$ and achieve their inhibitory effect. Viral inactivation assay showed that functionalized dendrimers with sulfate could bind directly on viral proteins on the surface of HSV-2 particles and block and inactivate HSV-2 infectivity. However, G2-S16, a sulfonate dendrimer, proved to carry out its inhibitory effect by binding to cellular surface molecules of host cell. Hence, it is possible that different polyanionic dendrimers show different binding specificities, although these dendrimers are generally considered nonspecific. This difference is due to the variability in the number of charged groups, the size, the structure of the polyanion, or the type of functional groups involved.

Molecular modeling showed that G1-S4 and G2-S16 were able to bind the $\mathrm{gB}$ protein in all selected binding sites including suggested binding area for gH-gL. Better results were achieved with G1-S4 than G2-S16 except the binding site on the top of the $\mathrm{gB}$. Therefore, both dendrimers can successfully block the viral fusion machinery. However, G1-S4 and G2-S16 differ in reaching the key binding sites. Thus, the smaller, more flexible, and faster moving dendrimer G1-S4 is better suited to reach worse accessible binding sites than G2-S16. If we focus on the proposed $\mathrm{gH}-\mathrm{gL}$ binding area, G2-S16 could have problem to reach position A, B of HSV-2 gB and G1-S4 could reach at least the edge of A, B area (case E) and disturb $\mathrm{gH}-\mathrm{gL} / \mathrm{gB}$ binding process. G1-S4 unlike G2-S16 could penetrate inside the $\mathrm{gB}$ trimer in its more open prefusion state and block the right fusion state of the $\mathrm{gB}$ trimer. Another interesting result which favors dendrimer G1-S4 in the context of interference with $\mathrm{gB} / \mathrm{gH}-\mathrm{gL}$ interaction is significantly higher affinity of dendrimer G2-S16 in position F comparing to the most
"gB/gH-gL" relevant positions A, B which is not the case for dendrimer G1-S4. In other words, unlike dendrimer G1-S4, for $\mathrm{G} 2-\mathrm{S} 16$ dendrimer is significantly more preferable position F comparing to A, B. Ability of G1-S4 and G2-S16 to bind in position $\mathrm{F}$ and to the missing N-terminus part (Figure S7F) can influence the interaction of $\mathrm{gB}$ with its eventual cell receptor and cell glycosaminoglycans, but experimental results with G2-S16 suggest that this effect has small impact on the HSV-2 fusion machinery. Dendrimer binding on the top of HSV-2 gB (mainly position F, eventually beginning part of $\mathrm{N}$-terminus) could somewhat decrease the probability that the more important place on this protein (eg, gB/gH-gL binding area) will be achieved by another dendrimer in the solution due to the electrostatic repulsion. (Figure S9)

This electrostatic repulsion will be more significant in case of G2-S16 which has four times higher charge than G1-S4. Interestingly enough, the fact that G2-S16 exhibited only small inhibition effect when previously mixed and incubated with HSV-2 suggests that successful blocking of the $\mathrm{gB} /$ receptor binding can prevent HSV-2 fusion, but preferred precise binding site position and/or the insufficient affinity of G2-S16 to the $\mathrm{N}$-terminal cationic part can be the reason for the less efficient blocking effect of G2-S16 in comparison with G1-S4. These molecular modeling observations would explain our in vitro results. G1-S4 binds directly to the virus particle hindering HSV-2 fusion through gB with host cell, while G2-S16 acts binding to cell-surface receptors, then the affinity of binding site may depend on the target cells of different epitheliums decreasing its effectiveness antiviral. The hypothesis that G1-S4 and G2-S16 dendrimers work in a different manner opens up the gate to alternative strategies such as the combination of the dendrimers not only with antiviral, but also with various non-specific compounds acting at different stages of the HSV-2 life cycle. This strategy has proven to be effective against other viruses, such as HIV or HCV. ${ }^{14,38}$

To potentially limit the selection of resistant strains that may compromise the treatment options and improve the efficacy of current antivirals, the use of combinations of different agents could be an interesting approach. ${ }^{8,9,14,17}$ Our dendrimers have shown an additive or synergistic profile when combined with ACV or TFV. The obtained synergy can be due to the fact that the dendrimers and ACV or TFV act at different steps in the viral cycle. We have demonstrated that dendrimers act at the attachment and entry step, whereas ACV plays a role at replication level and TFV inhibits HSV-2 DNA polymerase. ${ }^{39}$

Microbicides are applied directly to the genital tract or rectum before intercourse to protect against STI. However, the activity of vaginal microbicides can be altered by the physiological characteristics of the vagina. Consequently, 
we studied the anti-HSV-2 activity of our candidates at various $\mathrm{pHs}$ and we proved that the vaginal $\mathrm{pH}$ exercised no significant influence on the antiherpetic activity of dendrimers. Certain polyanions, despite their inhibitory activity against viruses, cause vaginal irritation. ${ }^{40}$ We previously demonstrated that G1-S4 and G2-S16 displayed a good safety profile and did not cause histopathological alterations in the vaginal epithelium in BALB/c mice and New Zealand White rabbits. ${ }^{8,17,31}$ In particular, we have also demonstrated in female h-BLT mice that transmission of HIV-1 was efficiently blocked by vaginally applied G2-S16.

Topical microbicides can reach high local drug concentrations for preventing HSV-2 and HIV-1 transmission without toxicity due to the many potential benefits associated with the drug delivery route. ${ }^{41}$ Mortality statistics have been used as an evaluation index for drug screening in HSV-2 animal models. ${ }^{42}$ Vaginitis appears in female BALB/c mice when a $10^{5} \mathrm{PFU}$ challenge dose of HSV-2 is administered. Our results showed that ten BALB/c female mice resisted becoming infected after treatment with topical $1 \%$ hydroxyethylcellulose (HEC) gel with 3\% G2-S16 before vaginal HSV-2 challenge, whereas $1 \%$ HEC gel with $3 \%$ G1-S4 protected nine out of ten $\mathrm{BALB} / \mathrm{c}$ female mice. Eight out of ten placebo-treated BALC/c mice became infected. However, when $\mathrm{BALB} / \mathrm{c}$ mice were exposed at the $10^{5} \mathrm{PFU}$ lethal concentration of HSV-2 rectally, $90 \%$ of mice treated with PBS 3\% G1-S4 were protected, while only $33 \%$ of mice treated with PBS 3\% G2-S16 were protected. In addition, we achieved $65 \%$ of protection when G2-S16 was combined with TFV against HSV-2 rectal infection. TFV is an ideal candidate to achieve this objective due to its ability to inhibit HSV-2 by inhibiting DNA polymerase. It has previously been published that the ability of this antiretroviral inhibits the HSV-2 replication in vivo, vaginally and rectally. ${ }^{43}$

HSV-2 vaginal and rectal challenge results reached in vivo are promising, G2-S16 has shown $100 \%$ protection against vaginal HSV-2 infection and G1-S4 has shown $90 \%$ of protection against vaginal HSV-2 infection and 90\% against rectal HSV-2 infection. The high inhibitory capacity of G1-S4 against HSV-2, equally to vaginal or rectal, could be due in large part to its ability to perform its function by direct binding to the particle virus, regardless of the environment in which it is found. The great morphological and structural difference between the vaginal and rectal epithelium could be the cause between different inhibitory activities shown with G2-S16, even more considering that this dendrimer attaches to proteins on the surface epithelial cells to carry out their antiherpetic activity. The multilayered epithelium of the vagina could offer a structural advantage over the simple columnar epithelium and stratified squamous epithelium of the rectum. ${ }^{44}$

Our work reveals that G1-S4 and G2-S16 are ideal antivirals because they play a major role in a multifunctional manner and are effective at noncytotoxic concentrations easily achievable in BALB/c. G1-S4 acts directly on the $\mathrm{HSV}-2$, inactivating it. Interestingly, G2-S16 provides protection due to its ability to bind to the host cell rather than to the viral particles. This has been showed previously for HIV-1 prevention, in which $\mathrm{G} 2-\mathrm{S} 16$ binds to the CD4-receptor and HIV CCR5/CXCR4-coreceptors of the cells, in addition to binds to the gp120 of HIV. ${ }^{8}$ With our results, one can speculate on the existence of a second mechanism of action that can allow G2-S16 to maintain the $50 \%$ of its antiherpetic effect when it is applied 8 hours later on exposure to HSV-2, suggesting that G2-S16 also exerts its inhibition at one different level than the virus cell attachment. This mechanism should be linked with later stage of the HSV-2 lifecycle. In keeping with these results, we showed in h-BLT mice that transmission of HIV-1 was efficiently blocked by vaginally applied G2-S16. ${ }^{11}$ Both findings provide a strong step forward in the development of G2-S16-based vaginal microbicides to prevent vaginal HSV-2 and HIV-1 transmission in humans.

Summarizing, achieving 100\% inhibition of HSV-2 vaginal infection not only halts the transmission of HSV-2, but also avoids HIV-1 infections associated with HSV-2. This coupled with the previously published ability of G2-S16 to inhibit vaginal transmission of HIV in vivo, makes this dendrimer ideal for the development of a microbicide. Although, $65 \%$ inhibition of rectal HSV-2 infection was achieved, our next step will be study these dendrimers in combination with antivirals, such as TFV or ACV, in order to block the effect of the viruses in different steps of the HIV-1 and HSV-2 cycles and achieve $100 \%$ inhibition.

\section{Acknowledgments}

This work was (partially) funded by the RD12/0017/0037, as part of the Acción Estratégica en Salud, Plan Nacional de Investigación Científica, Desarrollo e Innovación Tecnológica 2008-2011 and cofinanced by Instituto de Salud Carlos III (Subdirección General de Evaluación) and Fondo Europeo de Desarrollo Regional, RETIC PT13/0010/0028, Fondo de Investigacion Sanitaria (grant number PI13/02016), CTQ2011-23245 (MIMECO), Comunidad de Madrid (grant numbers S-2010/BMD-2351 and S-2010/BMD-2332), CYTED 214RT0482. CIBER-BBN is an initiative funded by the VI National R\&D\&I Plan 2008-2011, iniciativa INGENIO 2010, the Consolider Program, and CIBER 
Actions and financed by the Instituto de Salud Carlos III with assistance from the European Regional Development Fund. The financial support of the Czech Science Foundation (project no GA15-05903S) is acknowledged.

\section{Disclosure}

The authors report no conflicts of interest in this work.

\section{References}

1. Looker KJ, Magaret AS, Turner KM, Vickerman P, Gottlieb SL, Newman LM. Global estimates of prevalent and incident herpes simplex virus type 2 infections in 2012. PLoS One. 2015;10(1):e114989.

2. Gupta R, Warren T, Wald A. Genital herpes. Lancet. 2007;370(9605): 2127-2137.

3. Wagner EK, Flanagan WM, Devi-Rao G, et al. The herpes simplex virus latency-associated transcript is spliced during the latent phase of infection. J Virol. 1988;62(12):4577-4585.

4. Johnston C, Saracino M, Kuntz S, et al. Standard-dose and high-dose daily antiviral therapy for short episodes of genital HSV-2 reactivation: three randomised, open-label, cross-over trials. Lancet. 2012;379(9816): 641-647.

5. Johnston C, Koelle DM, Wald A. Current status and prospects for development of an HSV vaccine. Vaccine. 2014;32(14):1553-1560.

6. Freeman EE, Weiss HA, Glynn JR, Cross PL, Whitworth JA, Hayes RJ. Herpes simplex virus 2 infection increases HIV acquisition in men and women: systematic review and meta-analysis of longitudinal studies. AIDS. 2006;20(1):73-83.

7. Briz V, Sepulveda-Crespo D, Diniz AR, et al. Development of watersoluble polyanionic carbosilane dendrimers as novel and highly potent topical anti-HIV-2 microbicides. Nanoscale. 2015;7(35) 14669-14683.

8. Chonco L, Pion M, Vacas E, et al. Carbosilane dendrimer nanotechnology outlines of the broad HIV blocker profile. J Control Release. 2012; 161(3):949-958

9. Cordoba EV, Arnaiz E, De La Mata FJ, et al. Synergistic activity of carbosilane dendrimers in combination with maraviroc against HIV in vitro. AIDS. 2013;27(13):2053-2058.

10. Galan M, Sanchez Rodriguez J, Jimenez JL, et al. Synthesis of new anionic carbosilane dendrimers via thiol-ene chemistry and their antiviral behaviour. Org Biomol Chem. 2014;12(20):3222-3237.

11. Sepulveda-Crespo D, Serramia MJ, Tager AM, et al. Prevention vaginally of HIV-1 transmission in humanized BLT mice and mode of antiviral action of polyanionic carbosilane dendrimer G2-S16. Nanomedicine. 2015;11(6):1299-1308.

12. Bourne N, Stanberry LR, Kern ER, Holan G, Matthews B, Bernstein DI Dendrimers, a new class of candidate topical microbicides with activity against herpes simplex virus infection. Antimicrob Agents Chemother. 2000;44(9):2471-2474.

13. Tyssen D, Henderson SA, Johnson A, et al. Structure activity relationship of dendrimer microbicides with dual action antiviral activity. PLoS One. 2010;5(8):e12309.

14. Sepulveda-Crespo D, Lorente R, Leal M, et al. Synergistic activity profile of carbosilane dendrimer G2-STE16 in combination with other dendrimers and antiretrovirals as topical anti-HIV-1 microbicide. Nanomedicine. 2014;10(3):609-618.

15. Cordoba EV, Bastida H, Pion M, et al. HIV-Antigens charged on phosphorus dendrimers as tools for tolerogenic dendritic cells-based immunotherapy. Curr Med Chem. 2013;21(16):1898-1909.

16. Gong E, Matthews B, McCarthy T, et al. Evaluation of dendrimer SPL7013, a lead microbicide candidate against herpes simplex viruses. Antiviral Res. 2005;68(3):139-146.

17. Vacas Cordoba E, Arnaiz E, Relloso M, et al. Development of sulphated and naphthylsulphonated carbosilane dendrimers as topical microbicides to prevent HIV-1 sexual transmission. AIDS. 2013;27(8):1219-1229.
18. Bayly CI, Cieplak P, Cornell WD, Kollman PA. A well-behaved electrostatic potential based method using charge restraints for deriving atomic charges - the resp model. J Phys Chem. 1993;97(40): 10269-10280.

19. Dupradeau FY, Pigache A, Zaffran T, et al. The R.ED. tools: advances in RESP and ESP charge derivation and force field library building. Phys Chem Chem Phys. 2010;12(28):7821-7839.

20. Schmidt MW, Baldridge KK, Boatz JA, et al. General atomic and molecular electronic-structure system. J Comput Chem. 1993;14(11): 1347-1363.

21. Case DA, Babin V, Berryman JT, et al. AMBER 14. University of California: San Francisco; 2014.

22. Maurer UE, Zeev-Ben-Mordehai T, Pandurangan AP, et al. The structure of herpesvirus fusion glycoprotein B-bilayer complex reveals the protein-membrane and lateral protein-protein interaction. Structure. 2013; 21(8):1396-1405.

23. Pettersen EF, Goddard TD, Huang CC, et al. UCSF chimera - a visualization system for exploratory research and analysis. J Comput Chem. 2004;25(13):1605-1612.

24. Jorgensen WL, Chandrasekhar J, Madura JD, Impey RW, Klein ML. Comparison of simple potential functions for simulating liquid water. J Chem Phys. 1983;79(2):926-935.

25. Wu X, Brooks BR. Self-guided Langevin dynamics simulation method. Chem Phys Lett. 2003;381(3-4):512-518.

26. Nguyen H, Roe DR, Simmerling C. Improved Generalized Born Solvent Model Parameters for Protein Simulations. J Chem Theory Comput. 2013; 9(4):2020-2034

27. Gotz AW, Williamson MJ, Xu D, Poole D, Le Grand S, Walker RC Routine microsecond molecular dynamics simulations with amber on GPUs. 1. Generalized born. J Chem Theory Comput. 2012;8(5): $1542-1555$.

28. Miller BR, McGee TD, Swails JM, Homeyer N, Gohlke H, Roitberg AE. MMPBSA.py: an efficient program for end-state free energy calculations. J Chem Theory Comput. 2012;8(9):3314-3321.

29. Baker NA, Sept D, Joseph S, Holst MJ, McCammon JA. Electrostatics of nanosystems: application to microtubules and the ribosome. Proc Natl Acad Sci U S A. 2001;98(18):10037-10041.

30. Hawkins GD, Cramer CJ, Truhlar DG. Parametrized models of aqueous free energies of solvation based on pairwise descreening of solute atomic charges from a dielectric medium. J Phys Chem. 1996;100(51):19824-19839.

31. Sepulveda-Crespo D, Sanchez-Rodriguez J, Serramia MJ, et al. Triple combination of carbosilane dendrimers, tenofovir and maraviroc as potential microbicide to prevent HIV-1 sexual transmission. Nanomedicine (Lond). 2015;10(6):899-914.

32. Parr MB, Kepple L, McDermott MR, Drew MD, Bozzola JJ, Parr EL. A mouse model for studies of mucosal immunity to vaginal infection by herpes simplex virus type 2. Lab Invest. 1994;70(3):369-380.

33. Cutler B, Justman J. Vaginal microbicides and the prevention of HIV transmission. Lancet Infect Dis. 2008;8(11):685-697.

34. Basha SH, Talluri D, Raminni NP. Computational repositioning of ethno medicine elucidated $\mathrm{gB}-\mathrm{gH}-\mathrm{gL}$ complex as novel anti herpes drug target. BMC Complement Altern Med. 2013;13.

35. Cusini M, Ghislanzoni M. The importance of diagnosing genital herpes. J Antimicrob Chemother. 2001;47 Suppl T1:9-16.

36. Rasines B, Sanchez-Nieves J, Maiolo M, et al. Synthesis, structure and molecular modelling of anionic carbosilane dendrimers. Dalton Trans. 2012;41(41):12733-12748.

37. Akhtar J, Shukla D. Viral entry mechanisms: cellular and viral mediators of herpes simplex virus entry. FEBS J. 2009;276(24); $7228-7236$.

38. Xiao F, Fofana I, Thumann C, et al. Synergy of entry inhibitors with direct-acting antivirals uncovers novel combinations for prevention and treatment of hepatitis C. Gut. 2015;64(3):483-494.

39. Andrei G, Lisco A, Vanpouille C, et al. Topical tenofovir, a microbicide effective against HIV, inhibits herpes simplex virus-2 replication. Cell Host Microbe. 2011;10(4):379-389. 
40. Van Damme L, Govinden R, Mirembe FM, et al. Lack of effectiveness of cellulose sulfate gel for the prevention of vaginal HIV transmission. N Engl J Med. 2008;359(5):463-472.

41. Cottrell ML, Kashuba AD. Topical microbicides and HIV prevention in the female genital tract. J Clin Pharmacol. 2014;54(6):603-615.

42. Ishikawa T, Yamada H, Oyamada A, Goshima F, Nishiyama Y, Yoshikai Y. Protective role of Fas-FasL signaling in lethal infection with herpes simplex virus type 2 in mice. J Virol. 2009;83(22): 11777-11783.
43. McConville C, Boyd P, Major I. Efficacy of tenofovir $1 \%$ vaginal gel in reducing the risk of HIV-1 and HSV-2 infection. Clin Med Insights Womens Health. 2014;7:1-8.

44. Tanaka E, Noguchi T, Nagai K, Akashi Y, Kawahara K, Shimada T. Morphology of the epithelium of the lower rectum and the anal canal in the adult human. Med Mol Morphol. 2012;45(2):72-79.

\section{Publish your work in this journal}

The International Journal of Nanomedicine is an international, peerreviewed journal focusing on the application of nanotechnology in diagnostics, therapeutics, and drug delivery systems throughout the biomedical field. This journal is indexed on PubMed Central, MedLine, CAS, SciSearch ${ }^{\circledR}$, Current Contents ${ }^{\circledR} /$ Clinical Medicine,
Journal Citation Reports/Science Edition, EMBase, Scopus and the Elsevier Bibliographic databases. The manuscript management system is completely online and includes a very quick and fair peer-review system, which is all easy to use. Visit http://www.dovepress.com/ testimonials.php to read real quotes from published authors. 